\title{
Factors associated with health literacy in rural areas of Central China: structural equation model
}

\author{
Yaofei Xie ${ }^{1}$, Mengdi Ma², Ya'nan Zhang ${ }^{1}$ and Xiaodong Tan ${ }^{1 *}$
}

\begin{abstract}
Background: Health literacy is a strong predictor of health status. This study develops and tests a structural equation model to explore the factors that are associated with the health literacy level of rural residents in Central China.

Methods: The participants were recruited from a county-level city in Central China ( $N=1164)$. Face-to-face interviews were conducted to complete the self-designed questionnaire of each participant. The questionnaire included items for the (1) demographic information, (2) socioeconomic status, and (3) health literacy of the participants. Mplus analyses were performed to evaluate the proposed model.

Results: The final model showed good fit for the data, and both demographic characteristics (i.e., age, BMI, and residence) and socioeconomic status (i.e., monthly income, occupation, and education level) were significantly associated with health literacy level. The effects of these two variables were $-0.277(P<0.05)$ and $0.615(P<0$. 001), respectively, and the model explained $70.2 \%$ of the variance in health literacy.

Conclusions: Health literacy was significantly associated with age, BMI, distance between residence and nearest medical institution, monthly income, occupation, and education level, whereas socioeconomic status was a dominant predictor of health literacy level. Targeting these factors might be helpful in allocating health resources rationally when performing health promotion work.
\end{abstract}

Keywords: Health literacy, Factor, Rural area, Structural equation model

\section{Background}

Health literacy (HL) refers to the ability of an individual to obtain, understand and use health information to maintain and improve his/her own health [1]. Compared with traditional sociodemographic factors (e.g., age, race, education, income, and employment status), $\mathrm{HL}$ is as a stronger predictor of an individual's health status [2] and is a significant component of his/her health behaviors, health quality, and access to healthcare. HL also shows an inverse relationship with healthcare utilization and expenditure [3] and plays a crucial role in health education and promotion. Therefore, HL has become an important public health concern and has received increasing attention from different population groups,

\footnotetext{
* Correspondence: 00300469@whu.edu

${ }^{1}$ School of Health Sciences, Wuhan University, No.115 of Donghu Road,

Wuhan 430000, China

Full list of author information is available at the end of the article
}

including patients with asthma [4], HIV [5], lower back pain [6], and other health issues [7-10].

Although the impacts of HL have been widely studied, only few have investigated those factors associated with HL. Some studies revealed that the age, region (urban vs. rural), occupation, education, annual household income, and self-reported health status of individuals were associated with their HL [11-13]. Other works reported that those adolescents coming from prestigious schools and raised by highly educated parents tend to have adequate knowledge, skills, and behaviors [14]. As for occupational population, age, education levels, and type of industry show a significant relationship with HL [15].

Previous studies have mostly employed multiple logistic analyses to explore the factors associated with HL. However, given that the structural equation model (SEM) can provide a more comprehensive and flexible approach to data analysis compared with other multivariate statistical 
models [16], the purpose of this study was to develop and test a hypothesized model that uses SEM to explore those factors associated with HL and to gain a comprehensive picture of HL among the population of a county-level city in Central China.

\section{Methods}

This cross-sectional study employs SEM to examine the relationships among the studied variables for two reasons. First, SEM can simultaneously estimate the structural relationships between multiple independent variables and the dependent variable. Second, SEM shows advantages in identifying the direct, indirect, and total effects among variables [17].

\section{Sample}

This study was conducted in the city of Shishou, Hubei Province, China on January 2017. A multistage cluster sampling method was adopted for the participant selection. The procedure is illustrated in Fig. 1. Shishou city has 2 center streets and 12 townships within its jurisdiction. Among these townships, four are located north, three are located southeast, and five are located southwest of Jin
River that flows through the city. By using the random number method, one central street, one township in the north and southeast parts of the city, and two townships in the southwest part were selected for the sampling. In each selected district, one community or administrative village was randomly selected as an investigation site from which the participants were chosen. The total sample size was set to 1300 or at least $2 \%$ of the 576.4 thousand people residing in Shishou City. All participants should be aged between 15 years and 79 years. The sample size for each selected district was weighted by the proportion of its population to that of the entire Shishou City. Face-to-face interviews based on a self-designed questionnaire were conducted to collect information from each participant who signed an informed consent. The research team included three $\mathrm{PhD}$ candidates and nine master candidates in the School of Health Sciences of Wuhan University and the public health physicians from local health agencies. All these investigators were trained on the research purpose, survey procedure, and other important matters before conducting the survey. Those questionnaires with missing values for important personal information or HL outcome variables were excluded from the analysis.

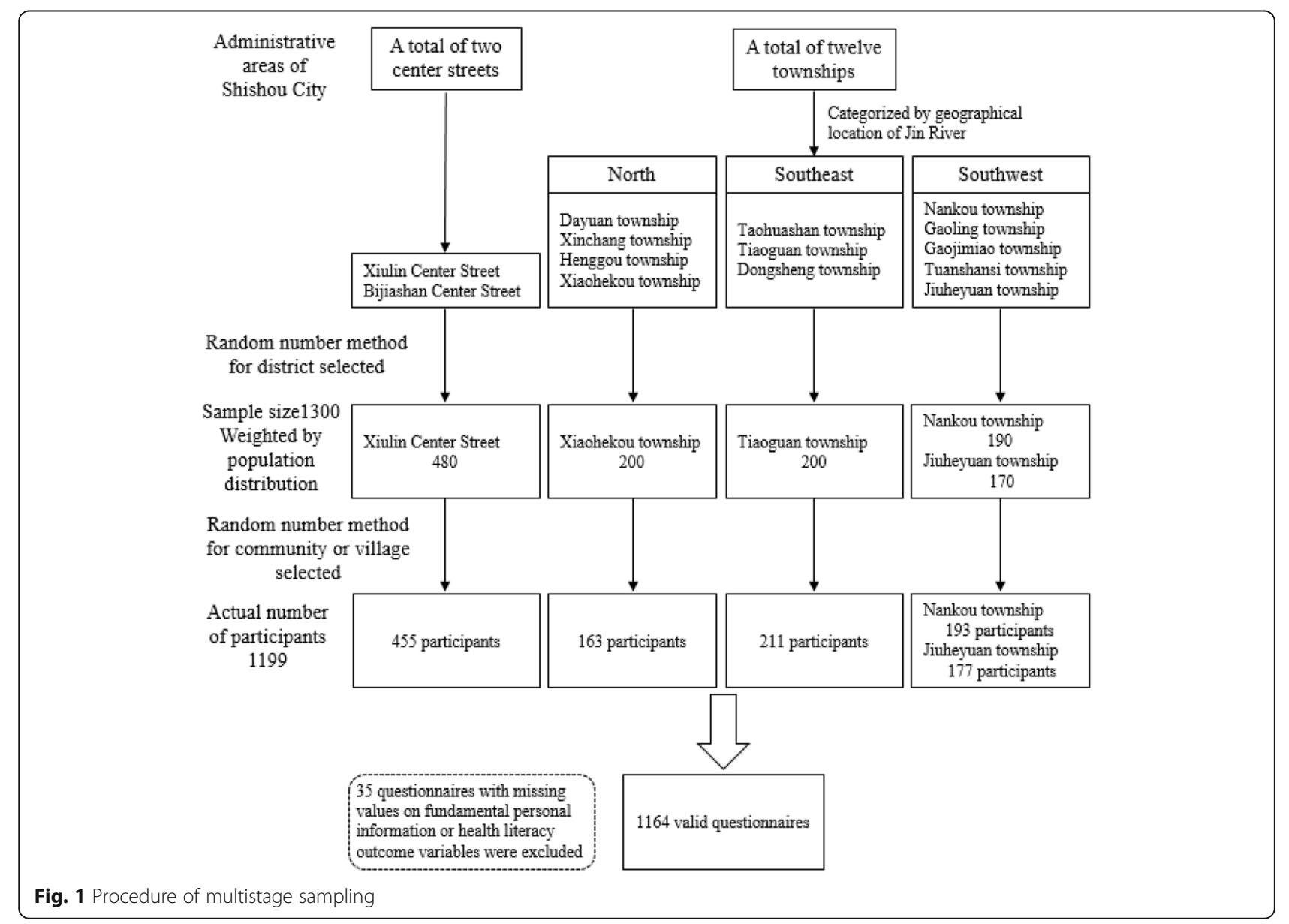




\section{Latent variables}

Many studies have reported that sociodemographic factors, including gender, age, race, marital status, education level, and income, are associated with one's HL level [11, 18-20]. Based on these univariate factors, we hypothesize that two latent variables, namely, demographic factor sand socioeconomic status (SES), can be extracted and used to collectively reflect the basic demographic characteristics and SES of the participants, respectively. Therefore, our hypothesized model includes three latent variables, namely, demographic information, SES, and HL.

A three-part self-designed questionnaire was used for the data collection. Six types of demographic information were collected, namely, gender, age, height, weight, marital status, and residence. BMI was calculated based on height and weight. SES comprised three observed variables, namely, monthly income, occupation, and education. HL content (Additional file 1) was assessed based on the "2015 Questionnaire of Health Literacy" scale developed by the Chinese Ministry of Health. This variable

Table 1 Assignment of observed variables

\begin{tabular}{|c|c|}
\hline Variables & Value \\
\hline \multicolumn{2}{|l|}{ Demographic information } \\
\hline 1.Gender & $1=$ male, 2 = female \\
\hline 2.Age in years & $\begin{array}{l}1=15-29,2=30-44,3=45-59 \\
4=60-69,5=70-79\end{array}$ \\
\hline 3.BMI & $\begin{array}{l}1=\text { underweight, } 2=\text { healthy weight, } \\
3=\text { overweight, } 4=\text { obese }\end{array}$ \\
\hline 4.Marital status & $\begin{array}{l}1=\text { unmarried }, 2=\text { married }, 3=\text { divorce, } \\
4=\text { widowed }\end{array}$ \\
\hline $\begin{array}{l}\text { 5.Residence: location from } \\
\text { nearest medial institutions }\end{array}$ & $\begin{array}{l}1=<1 \mathrm{~km}, 2=\leq 3 \mathrm{~km} \\
3=\leq 5 \mathrm{~km}, 4=>5 \mathrm{~km}\end{array}$ \\
\hline \multicolumn{2}{|l|}{ SES } \\
\hline 6.Monthly income & $\begin{array}{l}1=<1000 \mathrm{RMB}[¥], 2=1000-2999 \mathrm{RMB} \\
{[\because],} \\
3=3000-4999 \mathrm{RMB}[¥], 4=\geq 5000 \mathrm{RMB} \\
{[\because]}\end{array}$ \\
\hline 7.Occupation & $\begin{array}{l}1=\text { unemployed, } 2=\text { agricultural worker, } \\
3=\text { worker, } \\
4=\text { business personnel, freelancer, } \\
5=\text { enterprise worker, } \\
6=\text { institutional staff, } 7=\text { civil Servants }\end{array}$ \\
\hline 8.Education & $\begin{array}{l}1=\text { primary school or below, } 2=\text { junior } \\
\text { high school, } \\
3=\text { senior high school, } 4=\text { associate } \\
\text { bachelor or above }\end{array}$ \\
\hline \multicolumn{2}{|l|}{ Health literacy } \\
\hline 9. Health knowledge & $\begin{array}{l}1=\text { poor status }(\text { correct rate }<80 \%) \\
2=\text { not poor }(\text { correct rate } \geq 80 \%)\end{array}$ \\
\hline 10.Health behavior & $\begin{array}{l}1=\text { poor status }(\text { correct rate }<80 \%) \\
2=\text { not poor }(\text { correct rate } \geq 80 \%)\end{array}$ \\
\hline 11.Health skills & $\begin{array}{l}1=\text { poor status }(\text { correct rate }<80 \%) \\
2=\text { not poor }(\text { correct rate } \geq 80 \%)\end{array}$ \\
\hline
\end{tabular}

Table 2 Participant characteristics by health literacy

\begin{tabular}{|c|c|c|c|}
\hline Variables & $\mathrm{N} / \%$ & $\begin{array}{l}\text { Health literacy } \\
\mathrm{N} / \%\end{array}$ & $x^{2} / P$ \\
\hline gender & & & $11.686^{* * *}$ \\
\hline male & $603(51.80)$ & $84(13.93)$ & \\
\hline female & $561(48.20)$ & $121(21.57)$ & \\
\hline Age (years) & & & $135.154^{* * *}$ \\
\hline $15 \sim 29$ & $248(21.31)$ & $84(33.87)$ & \\
\hline $30 \sim 44$ & $256(21.99)$ & $78(30.47)$ & \\
\hline $44 \sim 59$ & $426(36.60)$ & $38(8.92)$ & \\
\hline $60 \sim 69$ & $151(12.97)$ & $3(1.99)$ & \\
\hline 70 79 & $83(7.13)$ & $2(2.41)$ & \\
\hline BMl & & & 3.215 \\
\hline emaciation & $100(8.59)$ & $16(16.00)$ & \\
\hline normal & $703(60.40)$ & $135(19.20)$ & \\
\hline overweight & $292(25.09)$ & $43(14.73)$ & \\
\hline obesity & $69(5.93)$ & $11(15.94)$ & \\
\hline Marital status & & & $32.555^{* * *}$ \\
\hline unmarried & $197(16.92)$ & $58(29.44)$ & \\
\hline married & $923(79.30)$ & $144(15.60)$ & \\
\hline divorced and widowed & $44(3.78)$ & $3(6.82)$ & \\
\hline Residences (km) & & & $10.844^{*}$ \\
\hline$<1$ & $604(51.89)$ & $97(16.06)$ & \\
\hline$\leq 3$ & $376(32.30)$ & $85(22.61)$ & \\
\hline$\leq 5$ & $117(10.05)$ & $14(11.97)$ & \\
\hline$>5$ & $67(5.76)$ & $9(13.43)$ & \\
\hline Income (RMB/month) & & & $35.646^{* * *}$ \\
\hline$<1000$ & $333(28.61)$ & $27(8.11)$ & \\
\hline$<3000 \mathrm{~h}$ & $601(51.63)$ & $119(19.80)$ & \\
\hline$<5000$ & $171(14.69)$ & $48(28.07)$ & \\
\hline$\geq 5000$ & $59(5.07)$ & $11(18.64)$ & \\
\hline Occupation & & & $284.675^{* * *}$ \\
\hline unemployed & $166(14.26)$ & $27(16.27)$ & \\
\hline farmer or worker & $594(51.03)$ & $37(6.23)$ & \\
\hline businessman and freelancer & $160(13.74)$ & $21(13.12)$ & \\
\hline enterprise staff & $34(2.92)$ & $8(23.53)$ & \\
\hline $\begin{array}{l}\text { institution or government } \\
\text { staff }\end{array}$ & $210(18.04)$ & $125(51.23)$ & \\
\hline Education & & & $342.265^{* * *}$ \\
\hline Primary school or below & $361(31.01)$ & $5(1.39)$ & \\
\hline Junior high school & $433(37.20)$ & $54(12.47)$ & \\
\hline Senior high school & $179(15.38)$ & $46(25.70)$ & \\
\hline associate bachelor or above & $191(16.41)$ & $100(52.36)$ & \\
\hline Total & $\begin{array}{l}1164 \\
(100.00)\end{array}$ & $205(17.61)$ & - \\
\hline
\end{tabular}

${ }^{*} P<0.05,{ }^{* *} P<0.01,{ }^{* * *} P<0.001$ 
was divided into the three dimensions of health knowledge, health behavior, and health skill. Health knowledge refers to one's understanding of basic and scientific health concepts, such as healthy lifestyle, safe medication, and chronic disease prevention and control. Health behavior mainly includes daily health-related lifestyles, including diet, exercise, smoking, and drinking. Health skill refers to one's ability to obtain and understand information related to their health and self-rescue ability. All observed variables are summarized in Table 1.

\section{Statistical analysis}

The descriptive statistics for the demographic variables and HL status were analyzed along with the correlation matrix for all observed variables by using SPSS version 20.0. SEM was performed using Mplus version 7.0 to test the hypotheses. The weighted least squares with mean and variance adjusted method was used for the parameter estimation.

A two-step approach was adopted to test the associations among the variables. First, a confirmatory factor analysis for the measurement model was conducted to examine how well the latent variables can be reflected by the observation variables. Second, the hypothesized SEM was tested to examine the associations among the three latent variables. The overall model fitness was confirmed by using fitness indices to check whether the hypothesized model fits the data well. These goodness-of-fit indices include: maximum likelihood chi-square $\left(x^{2}\right)$, comparative fit index $(C F I)$, TuckerLewis index $(T L I)$, and root mean square error of approximation (RMSEA).

\section{Results}

\section{Participants and $\mathrm{HL}$ status}

Among the 1199 participants, 1164 returned valid responses. Among these 1164 participants, $51.80 \%$ were males $(n=603)$, with a median age of 47 years inter-quartile range of 25 years, $17.61 \%$ had qualified HL $(n=205)$, and 29.72\% $(n=346), 18.73 \%(n=218)$ and $35.22 \%(n=410)$ had health knowledge, health behavior, and health skill, respectively. As shown in Table 2, those participants with different genders, age groups, marital status, distances between residence and nearest medical institution, income groups, occupations, and education levels showed significant differences in their rate of qualified HL.

The correlation matrix for all observed variables is presented in Table 3. Many of the observed variables showed a significant correlation. Health knowledge, health behavior, and health skill were all highly correlated with age and the observed variables of socio-economic status $(p<0.01)$.

\section{Measurement model}

Demographic information, SES, and HL were specified in the measurement model. To determine the most parsimonious model, the insignificant parameters and collinear observed variables were deleted from the initial measurement model based on the critical ratios and regression coefficients. After this modification, demographic information, SES, and HL were assigned three, two, and three observed variables, respectively. (Fig. 2).

Demographic information, SES, and HL had loadings of $0.18-0.79,0.54-0.87$, and $0.57-0.81$, respectively. All these factor loadings were significant $(p<0.01)$.

Table 3 Correlation matrix for study variables $(N=1164)$

\begin{tabular}{|c|c|c|c|c|c|c|c|c|c|c|c|}
\hline & 1 & 2 & 3 & 4 & 5 & 6 & 7 & 8 & 9 & 10 & 11 \\
\hline \multicolumn{12}{|c|}{ Demographic information } \\
\hline 1.Gender & 1 & & & & & & & & & & \\
\hline 2.Age & $-.100^{* *}$ & 1 & & & & & & & & & \\
\hline 3.BMI & $-.156^{* *}$ & $.096^{* *}$ & 1 & & & & & & & & \\
\hline 4.Marital status & .003 & $.550^{* *}$ & $.104^{* *}$ & 1 & & & & & & & \\
\hline 5.Residence & $.081^{* *}$ & $.095^{* *}$ & .045 & $.090^{* *}$ & 1 & & & & & & \\
\hline \multicolumn{12}{|l|}{ Socioeconomic status } \\
\hline 6.Monthly income & $-.073^{* *}$ & $-.360^{* *}$ & .003 & $-.184^{* *}$ & -.016 & 1 & & & & & \\
\hline 7.Occupation & .023 & $-.279^{* *}$ & $-.028^{*}$ & .015 & $-.074^{* *}$ & $.293^{* *}$ & 1 & & & & \\
\hline 8.Education & $-.057^{*}$ & $-.556^{* *}$ & $-.055^{*}$ & $-.230^{* *}$ & $-.132^{* *}$ & $.369^{* *}$ & $.688^{* *}$ & 1 & & & \\
\hline \multicolumn{12}{|l|}{ Health literacy } \\
\hline 9. Health knowledge & $.057^{*}$ & $-.375^{* *}$ & $-.066^{*}$ & $-.183^{* *}$ & -.006 & $.187^{* *}$ & $.347^{* *}$ & $.435^{* *}$ & 1 & & \\
\hline 10.Health behavior & $.061^{*}$ & $-.257^{* *}$ & -.067 & $-.095^{* *}$ & .007 & $.136^{* *}$ & $.336^{* *}$ & $.374^{* *}$ & $.372^{* *}$ & 1 & \\
\hline 11.Health skill & $-.053^{*}$ & $-.213^{* *}$ & -.018 & $-.104^{* *}$ & $-.090^{* *}$ & $.139^{* *}$ & $.255^{* *}$ & $.282^{* *}$ & $.288^{* *}$ & $.301^{* *}$ & 1 \\
\hline
\end{tabular}




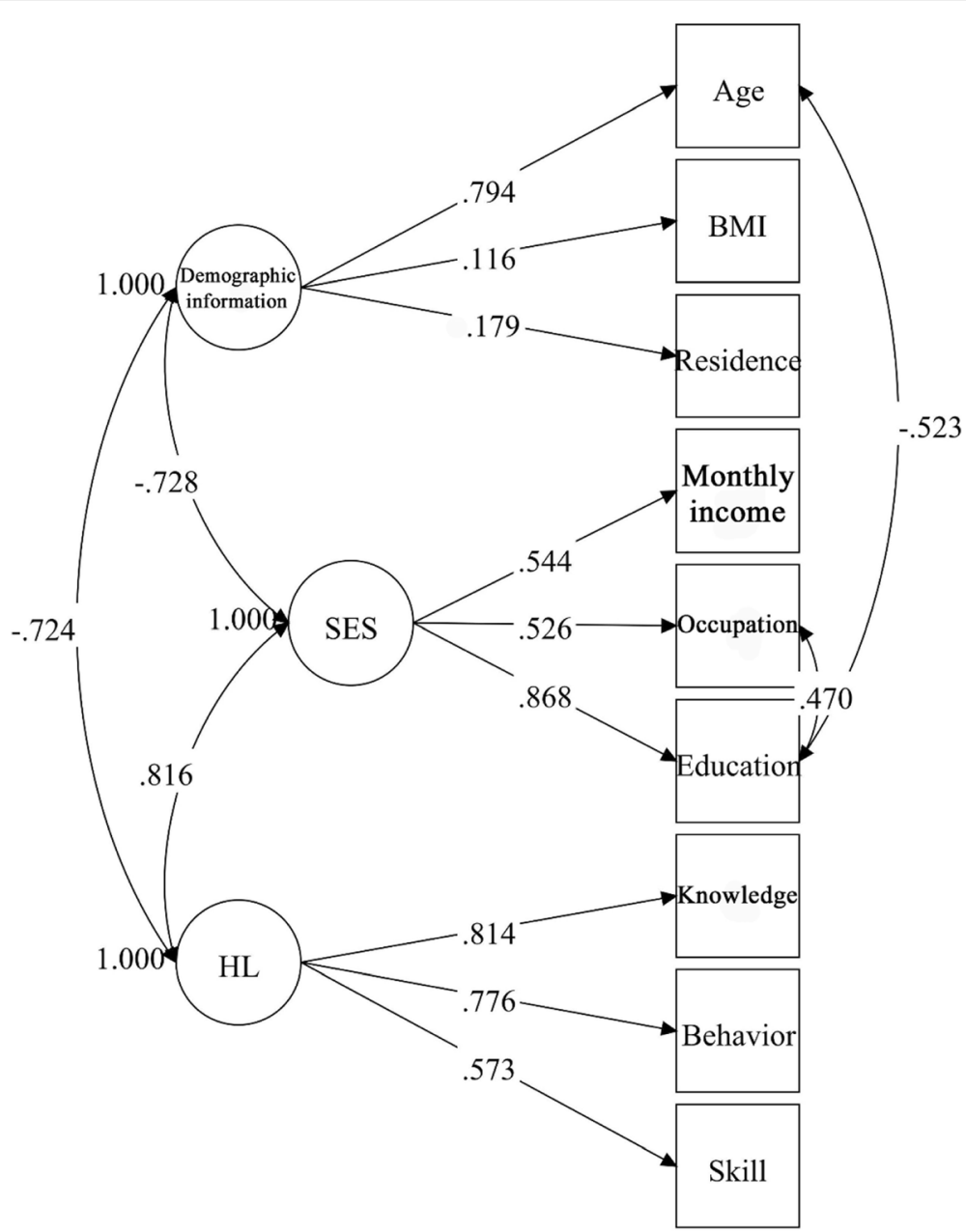

Fig. 2 Final measurement model of the observed variables. Three latent variables and nine manifest variables are connected by significant paths. The numbers on the straight arrows indicate the path coefficients. Every pair of latent variables is connected by bidirectional arrow curves, and the numbers on the lines indicate the correlation coefficients. The variances are set to 1.000 during the model estimation

Three latent variables from the measurement model were significantly intercorrelated. HL showed the strongest relationship with SES $(r=0.82, p<0.01)$ and demonstrated a strong association with demographic information $(r=-0.72$, $p<0.01)$. Meanwhile, SES showed a strong association with demographic information $(r=-0.73, p<0.01)$, and the measurement model demonstrated an acceptable fit to the data: $\chi^{2}=106.608, d f=17, p<0.001, C F I=0.946, T L I=0.912$, RMSEA $=0.067$ (95\% CI $=0.055-0.080)$.

\section{Structural equation model}

A structural equation model was designed based on the measurement model. Demographic information $(r=-$ $0.28, p<0.05)$ and SES $(r=0.615, p<0.01)$ had direct paths to HL and were correlated. The developed structural equation model was the most parsimonious model in which all the parameters were significant $(p<0.05$ or $p<0.01)$. This model also showed a good fit to the data:
$X^{2}=106.608, d f=17, p<0.001, C F I=0.946, T L I=0.912$, RMSEA $=0.067$ (95\% CI=0.055-0.080). (Fig. 3).

Demographic information and SES were both significantly and directly associated with HL. According to the structural equation model, the identified predictors explained $70.2 \%$ of the variance in HL. Table 4 illustrates the direct associations of all observed variables with HL.

\section{Discussion}

This study is the first to examine the structural interrelationship of the three facets of HL with possible associated factors among the population of Central China. HL showed a significant relationship with both demographic information and SES, and these two predictors could altogether explain $70.2 \%$ of the variance in HL. The direct pathway of the model highlighted SES as a dominant predictor of HL level.

Demographic information showed a significantly negative relationship with the three facets of HL. The paths 


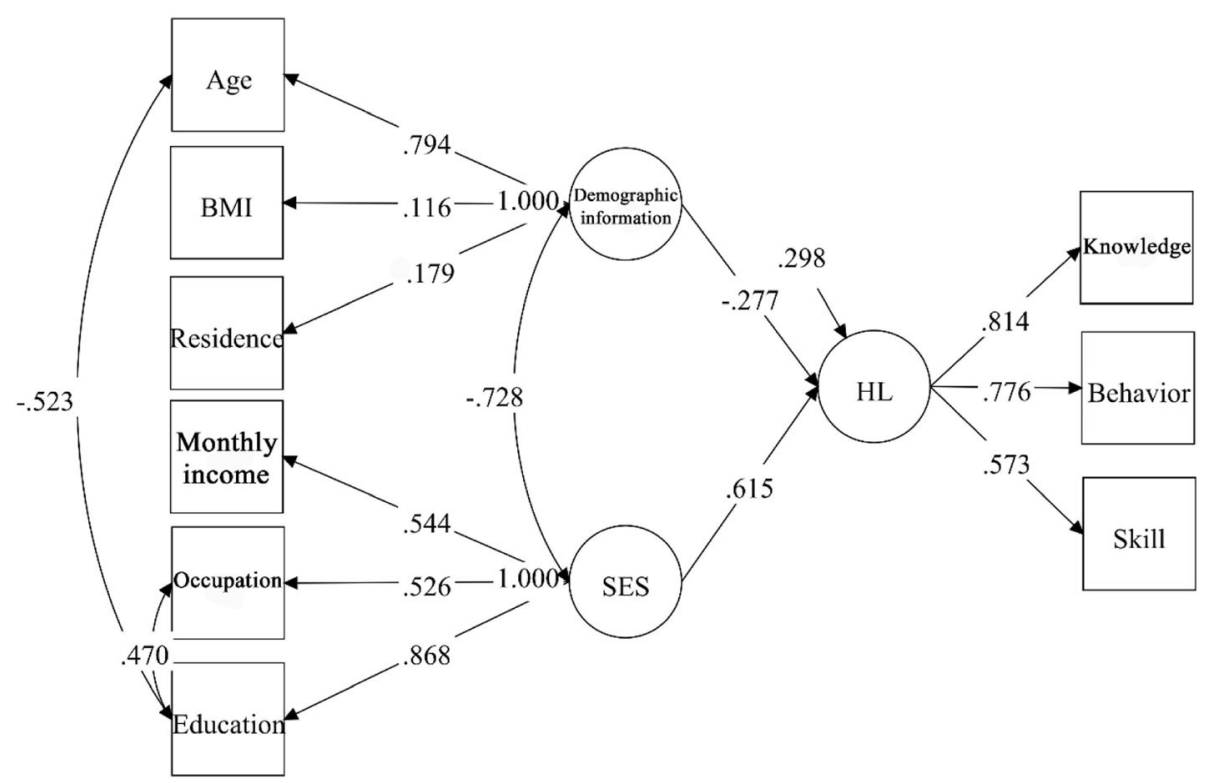

Fig. 3 Structural equation model of demographic information, socioeconomic status, and HL. The relationships between the three latent variables and their corresponding manifest variables are presented, and the standardized coefficients and residuals are included in the model. Demographic information and SES are significantly correlated with a correlation coefficient of -0.728 . HL is significantly associated with demographic information and SES with path coefficients of -0.277 and 0.615 , respectively

indicated that older participants with higher BMI and were residing further away from the nearest medial institution were more likely to have a lower HL level. The elderly population usually had less opportunities and approaches to access to health education. Overall, the Chinese elderly population had limited access to education during their youth, which coincided with the findings of some previous studies [2, 11, 12, 21]. Few studies have highlighted a relationship between BMI and HL. For instance, in a population cohort study among men in South Australia revealed an association between low HL and obesity [22], while a study among dialysis patients showed that HL was not a statistically significant predictor of BMI [23]. Meanwhile, in this study, the relationship of BMI and HL was statistically significant but not particularly strong. This result may be explained by

Table 4 Standardized effects of observed variables on health literacy

\begin{tabular}{ll}
\hline Variables & Effects \\
\hline Demographic information & \\
Age & -0.499 \\
BMl & -0.032 \\
Residence & 0.050 \\
Socioeconomic status & \\
Monthly income & 0.335 \\
Occupation & 0.574 \\
Education & 0.801 \\
\hline
\end{tabular}

the close relationship between one's BMI and lifestyle and the fact that those individuals with higher HL were more likely to adopt healthy eating, exercise, and sleep behaviors [24]. Residence from the nearest medial institution was also associated with health education opportunities.

The association among income, occupation and HL has been highlighted in previous studies $[2,11,12,25$, 26], whose findings are consistent with those of this work, specifically the result highlighting monthly income and occupation as strong predictors of HL. The association between education level and HL level has also been reported in many studies [13, 15, 27-30]. Similar to the findings of this work, those individuals with higher education level were reported to have a higher HL level. Because having higher access to education could improve one's ability to read, analyze, and judge information. In other words, people with better education had easier access to health knowledge and skills.

\section{Limitations}

This study has several limitations. First, the results are based on a cross-sectional sample, and are therefore unable to highlight the direction of causality of some factors. Second, the model results were based on classificatory data, some of which were converted from continuous variables, and this data processing might result in information loss. Third, this study only focused on the residents of a single county in China, thereby restricting the generalizability of its findings. To address 
these issues, the model should be validated by using multiple samples, and future studies should focus on the residents of other provinces of China verify the findings and to better understand the relationship between HL and its associated factors.

\section{Conclusions}

The findings of this work indicate that demographic information and SES are associated with the HL level of the residents of a county-level city in Central China. Older people, with higher BMI, residing far away from medical institutions, earning a lower monthly income, and having lower education levels were more likely to have a lower level of HL. Occupation also plays a significant role in predicting HL. Accordingly, the aging, obese, and undereducated population as well as those residents living far away from medical institutions warrant more attention when performing health education or promotion work. Health resources should also be allocated rationally to different occupational groups to enhance their utilization efficiency.

\section{Additional file}

Additional file 1: Health Literacy Survey Part. This additional file is the health literacy survey part of the questionnaire, it includes four types, a total of fifty six questions about health literacy. And these questions are used to test the level of health knowledge, health behavior and health skills of the participant. (DOC $98 \mathrm{~kb}$ )

\section{Abbreviations}

BMI: Body mass index; CFI: Comparative fit index; Cl: Confidence interval; HIV: Human immunodeficiency virus; HL: Health literacy; RMSEA: Root mean square error of approximation; SEM: Structural equation model;

SES: Socioeconomic status; TLI: Tucker-Lewis index

\section{Acknowledgements}

Health committee of Hubei Province and Shishou city were acknowledged for their supports.

\section{Funding}

No funding was obtained for this study.

\section{Availability of data and materials}

The datasets generated and/or analyzed during the current study are not publicly available due to not getting consents from all participants to publish this data, but are available from the corresponding author on reasonable requests.

\section{Authors' contributions}

YF analyzed the study data and was a major contributor in writing the manuscript. MD contributed to the data analysis and had been involved in revising this manuscript critically for important intellectual content. YN completed the data collection and sorting. XD made substantial contributions to the conception and acquisition of this study. All authors read and approved the final manuscript.

\section{Ethics approval and consent to participate}

The authors asserted that all procedures contributing to this work complied with the ethical standards of the relevant national and institutional committees on human experimentation and with the Helsinki Declaration of 1975, as revised in 2008. And the study protocol was approved by the Ethics Committee of School of Medicine, Wuhan University (Number: 2016YF0096).
All participants signed a consent to participate after reading the purpose, data using and personal information confidentiality rules of the study which were written on the front page of the questionnaire. The parents or guardians of participants aged 15-18 were also asked to sign the consent to participate. The statement of consent to participate was as following: I have read and understood the content and purpose of this questionnaire and agree to participate in this study.

Consent for publication

Not Applicable

\section{Competing interests}

The authors declare that they have no competing interests.

\section{Publisher's Note}

Springer Nature remains neutral with regard to jurisdictional claims in published maps and institutional affiliations.

\section{Author details}

${ }^{1}$ School of Health Sciences, Wuhan University, No.115 of Donghu Road, Wuhan 430000, China. 'Wuhan Blood Center, No.8 of Baofeng One Road, Wuhan 430000, China.

Received: 2 December 2018 Accepted: 12 April 2019

Published online: 10 May 2019

\section{References}

1. Katz A. Health literacy: what do you know? Oncol Nurs Forum. 2017;44: $521-2$.

2. Wang X, Guo H, Wang L, Li X, Huang M, Liu Z, et al. Investigation of residents' health literacy status and its risk factors in Jiangsu Province of China. Asia Pac J Public Health. 2015;27:NP2764-72.

3. Rasu RS, Bawa WA, Suminski R, Snella K, Warady B. Health literacy impact on National Healthcare Utilization and expenditure. Int J Health Policy Manag. 2015;4:747-55.

4. Curtis $L M$, Wolf MS, Weiss KB, Grammer LC. The impact of health literacy and socioeconomic status on asthma disparities. J Asthma. 2012;49:178-83.

5. Dorner TE, Schulte-Hermann K, Zanini M, Leichsenring B, Stefanek W. Health literacy, source of information and impact on adherence to therapy in people living with HIV. J Int AIDS Soc. 2014;17:19599.

6. Edward J, Carreon LY, Williams MV, Glassman S, Li J. The importance and impact of patients' health literacy on low back pain management: a systematic review of literature. Spine J. 2018;18:370-6.

7. Altin SV, Stock S. Impact of health literacy, accessibility and coordination of care on patient's satisfaction with primary care in Germany. BMC Fam Pract. 2015;16:148.

8. Beatty $C R$, Flynn $L A$, Costello TJ. The impact of health literacy level on inhaler technique in patients with chronic obstructive pulmonary disease. J Pharm Pract. 2017:30:25-30.

9. Chen AM, Noureldin M, Plake KS. Impact of a health literacy assignment on student pharmacist learning. Res Social Adm Pharm. 2013;9:531-41.

10. De Oliveira GS Jr, McCarthy RJ, Wolf MS, Holl J. The impact of health literacy in the care of surgical patients: a qualitative systematic review. BMC Surg. 2015;15:86.

11. Wu SS, Yang P, Li HY, Ma CN, Zhang Y, Wang QY. [analysis of status and influence factors of health literacy related to infectious diseases in residents of Beijing]. Beijing da xue xue bao Yi xue ban = journal of Peking University. Health sciences. 2012:44:607-11.

12. Wu Y, Wang L, Cai Z, Bao L, Ai P, Ai Z. Prevalence and risk factors of low health literacy: a community-based study in Shanghai, China. Int J Environ Res Public Health. 2017;14(6):628.

13. Protheroe J, Whittle R, Bartlam B, Estacio EV, Clark L, Kurth J. Health literacy, associated lifestyle and demographic factors in adult population of an English city: a cross-sectional survey. Health expect. 2017;20:112-9.

14. Ye XH, Yang Y, Gao YH, Chen SD, Xu Y. Status and determinants of health literacy among adolescents in Guangdong, China. Asian Pac J cancer Prev. 2014;15:8735-40.

15. Yang X, Zhao CX, Li S, Chen FZ, Li JG. Health literacy level and influence factors of occupational population in one province. Zhonghua lao dong wei sheng zhi ye bing za zhi = Zhonghua laodong weisheng zhiyebing 
zazhi $=$ Chinese journal of industrial hygiene and occupational diseases. 2017;35:683-7.

16. Park SE, Lee KS, Yun SN, Cui W. Structural model of factors influencing smoking behavior among Korean-Chinese adolescent boys. Appl Nurs Res. 2014;27:192-7

17. Kim SJ, Kim HY, Park YA, Kim SH, Yoo SY, Lee JE, et al. Factors influencing fatigue among mothers with hospitalized children: a structural equation model. J Spec Pediatr Nurs. 2017;22.

18. Huang YM, Shiyanbola OO, Chan HY. A path model linking health literacy, medication self-efficacy, medication adherence, and glycemic control. Patient Educ Couns. 2018;101:1906-13.

19. Schrauben SJ, Wiebe DJ. Health literacy assessment in developing countries: a case study in Zambia. Health Promot Int. 2017;32:475-81.

20. Zhang PP, Chang $C$. Health literacy and its relative factors to residents in three cities in China. Zhonghua yu fang yi xue za zhi [Chinese journal of preventive medicine]. 2012;46:822-4.

21. Alberti TL, Morris NJ. Health literacy in the urgent care setting: what factors impact consumer comprehension of health information? I Am Assoc Nurse Pract. 2017;29:242-7.

22. Li JJ, Appleton SL, Wittert GA, Vakulin A, McEvoy RD, Antic NA, et al. The relationship between functional health literacy and obstructive sleep apnea and its related risk factors and comorbidities in a population cohort of men. Sleep. 2014;37:571-8.

23. Adeseun GA, Bonney CC, Rosas SE. Health literacy associated with blood pressure but not other cardiovascular disease risk factors among dialysis patients. Am J Hypertens. 2012;25:348-53.

24. Yang SC, Luo YF, Chiang CH. The associations among individual factors, eHealth literacy, and health-promoting lifestyles among college students. J Med Internet Res. 2017;19:e15.

25. Kumar VA, Albert NM, Medado P, Mango LM, Nutter B, Yang D, et al. Correlates of health literacy and its impact on illness beliefs for emergency department patients with acute heart failure. Crit Pathw Cardiol. 2017;16:27-31.

26. Saeed H, Saleem Z, Naeem R, Shahzadi I, Islam M. Impact of health literacy on diabetes outcomes: a cross-sectional study from Lahore, Pakistan. Public Health. 2018:156:8-14.

27. Chesser AK, Reyes J, Keene Woods N. Identifying health literacy in Kansas using the behavioral risk factor surveillance system. International quarterly of community health education. 2018:272684X18821305.

28. Estacio EV, Whittle R, Protheroe J. The digital divide: examining sociodemographic factors associated with health literacy, access and use of internet to seek health information. J Health Psychol. 2017: 1359105317695429.

29. Macha-Quillama LF, Samanamu-Leandro AE, Rodriguez-Hurtado DC. [health literacy and associated factors in patients attending the outpatient internal medicine service of a national hospital of Lima, Peru]. Revista de salud. publica. 2017:19:679-85.

30. Verney SP, Gibbons LE, Dmitrieva NO, Kueider AM, Williams MW, Meyer OL, et al. Health literacy, sociodemographic factors, and cognitive training in the active study of older adults. Int I Geriatr Psychiatry. 2019;34:563-70.

Ready to submit your research? Choose BMC and benefit from:

- fast, convenient online submission

- thorough peer review by experienced researchers in your field

- rapid publication on acceptance

- support for research data, including large and complex data types

- gold Open Access which fosters wider collaboration and increased citations

- maximum visibility for your research: over $100 \mathrm{M}$ website views per year

At $\mathrm{BMC}$, research is always in progress.

Learn more biomedcentral.com/submissions 